\title{
SEMI AUTOMATED COCONUT TREE CLIMBER
}

\author{
Rahul V', Sebin Babu ${ }^{2}$, Sameer Moideen $\mathrm{CP}^{3}$, Vineeth $\mathrm{VP}^{4}$, Nikhil Ninan ${ }^{5}$ \\ ${ }^{1}$ Student, Saintgits College of Engineering, Kerala, India \\ ${ }^{2}$ Student, Saintgits College of Engineering, Kerala, India \\ ${ }^{3}$ Student, Saintgits College of Engineering, Kerala, India \\ ${ }^{4}$ Student, Saintgits College of Engineering, Kerala, India \\ ${ }^{5}$ Asst Prof, Department of Mechanical Engineering, Saintgits College of Engineering, Kerala, India
}

\begin{abstract}
Primary goal of the project is to design a coconut tree climbing device for farmers and residents. It is very difficult to climb on coconut tree manually due to the constant cylindrical structure and single stem. In other type of trees there will be branches for holding and to support the climber. A professional climber with proper training only be able to climb coconut tree. Due to the risk involved, nowadays a very few are coming forward to climb on coconut trees. Most of them hesitate. Agricultural workers employed for coconut tree climbing suffer musculoskeletal disorders than any other type of injury or illness. As the educational background of Indian youth is increasing, most of the people may hesitate to come in climbing profession. Considering this scenario, a device which helps the user to climb coconut tree easily will be useful for those having coconut cultivation as well as residents who is having less coconut trees.

In this project, we aim to design a mechanism which is simple and easy to operate. For this we first made a rough sketch considering average diameter of a coconut tree as $30 \mathrm{~cm}$ and designed it in Solid Works. Later a static analysis was done using ANSYS to ensure its stability. After that we moved on to the fabrication part. The material used is GI steel. Three linear electrical actuators are used in this mechanism - two for gripping and one for the vertical up and down motions. Each actuator can carry up to $400 \mathrm{~kg}$. The analysis done using ANSYS proved the design to be safe and the fabrication was completed successfully.
\end{abstract}

Keywords: GI Steel, Linear electric actuator.

\section{INTRODUCTION}

In olden days most of the activities were done manually. Gradually so many big and small equipments were developed to ease human activities, thus to lessen the human efforts to do the things. Nowadays most of the activities which included human efforts were either replaced or automated by the use of machines or other kind of equipments.

India is the third largest producer of coconut in the world. Coconut is grown in an area of about 18.7 million hectares with a productivity of 5718 nuts per hectare in India (National Horticulture Board, 2011). Usually all over the country, farmers practice conventional harvesting method in which coconuts are picked by specially trained, skilful and experienced climbers. Due to the height and lack of branches, it is very difficult to climb on coconut trees. A professional climber with proper training only could climb coconut tree. Due to the risk involved, nowadays a very few are coming forward to climb on coconut trees. Due to the lack of professional climbers, the existing professionals may charge more from the owners. Many young men now avoid coconut-picking in favour of white collar jobs, meaning there is no longer a guaranteed labour force. Coconut Tree climbers are a rarity these days. The scarcity of labour disrupts harvesting cycles causing loss of income to the growers. As against the general norm of harvesting cycles of 45-60 days, farmers are currently able to harvest only once in three to four months. Considering this scenario, device which helps the user to climb coconut tree easily will be useful for those having coconut cultivation as well as residents who is having less coconut trees. This kind of devices will encourage more people to come forward to agricultural sector.

\subsection{Outline}

In this project, we aim to design a mechanism which is simple and easy to operate. For this we first made a rough sketch considering average diameter of a coconut tree as 30 $\mathrm{cm}$ and designed it in Solid Works. Later a static analysis was done using ANSYS to ensure its stability. After that we moved on to the fabrication part. Three linear electrical actuators are used in this mechanism - two for gripping and one for the vertical up and down motions. Each actuator can carry up to $400 \mathrm{~kg}$. The analysis done using ANSYS proved the design to be safe and the fabrication was completed successfully.

\section{LITERATURE REVIEW}

Mani and Jothilingam [1] discussed the development and fabrication of a semi-autonomous tree climber and harvester (COCOBOT). COCOBOT comprises of two mechanisms namely a climbing mechanism and a harvesting mechanism. The climbing mechanism consists of a octagon shaped chassis. Four active wheels are set at specific intervals around the tree of which one pair is for the upper side and 
the other for the lower side of the chassis. The main features of the climbing mechanism include the location of centre of mass of the COCOBOT outside the tree and the innovative climbing strategy fusing the straight and spiral climbs. The harvesting mechanism consists of an arm with three degree of freedom with a circular saw as an end effector. The bunch of nuts is located by a vision sensor (camera) which is placed at the wrist of the arm. The nuts are harvested using the saw based on the output received from the camera. The entire movement of the COCOBOT and the harvesting mechanism is controlled using remote controller

Megalingam, Venumadhav et.al [2] in their paper, discussed various models for tree climbing and plucking. He took into account the safety, reliability, the ease of use which is capable of climbing trees, cutting down coconuts, cleaning the tree tops and spraying pesticides. He designed a system that can be controlled by anyon. The designed prototype responds to human gestures with negligible gap in the response time and hence can be implemented in real time.

Mohankumar, Kathirvel et.al [3] developed tree climbing device and evaluated based on ergonomical parameters and ergo refinements. The inclination of upper frame of climbing device is increased with respect to the horizontal, while moving towards the top of the tree. As a result, the centre of gravity of the user moves towards outside of the body making him feel insecure and unstable. The upper frame of coconut tree climbing device was suitably modified to avoid downward inclination such that ergo refined device improves the safety and ease of operation.

\section{METHODOLOGY}

The first step was the collection and study of various data regarding the design and mechanism of the new product. Next step was to design the model using SolidWorks 14. Then static load analysis of the model was done using ANSYS 14.5. In the static load analysis, total deformation and maximum stress induced were determined. Then we moved on to the fabrication part. Selection of material was the first step for fabrication.

For fabrication, GI steel was used as the material because of its high strength, weldability, availability and low cost. The next step was the selection of suitable powering device for the gripping and vertical motion of the mechanism. For this we chose linear electrical actuators. For the smooth operation we used three actuators, two for gripping, having a stroke length of $15 \mathrm{~cm}$ and providing $4000 \mathrm{~N}$. For vertical motion, actuator having stoke length of $40 \mathrm{~cm}$ and capable of providing $6000 \mathrm{~N}$ was used. A $12 \mathrm{~V} \mathrm{DC}$ battery was used to provide power for the actuators. The prototype was made as per the design and tested in the real conditions and suitable modifications were made to the final model.

\section{PRODUCT DESIGN}

For designing the parts of the product, first we developed a rough sketch of the product considering average diameter of a coconut tree as $30 \mathrm{~cm}$. After making suitable alterations and corrections we arrived at the final design. Based on the final design developed, the design was modelled using the software SolidWorks 14. The design parts listed below

\begin{tabular}{|c|c|c|c|}
\hline S1 no: & Part name & Material & $\begin{array}{l}\text { No of } \\
\text { units }\end{array}$ \\
\hline 1 & Main bar & GI Steel & 2 \\
\hline 2 & Angular link & GI Steel & 4 \\
\hline 3 & Straight link & GI Steel & 4 \\
\hline 4 & Bush & GI Steel & 4 \\
\hline 5 & $\begin{array}{l}\text { Central linear } \\
\text { actuator cylinder }\end{array}$ & & 1 \\
\hline 6 & $\begin{array}{l}\text { Central linear } \\
\text { actuator piston }\end{array}$ & & 1 \\
\hline 7 & $\begin{array}{l}\text { Gripper linear } \\
\text { actuator cylinder }\end{array}$ & & 2 \\
\hline 8 & $\begin{array}{l}\text { Gripper linear } \\
\text { actuator piston }\end{array}$ & & 2 \\
\hline
\end{tabular}

\subsection{Material Description}

GI Steel is used as the material for all the components manufactured because it is easily available, weldability, high strength and low cost. It has a density of $8000 \mathrm{~kg} / \mathrm{m}^{3}$ making it suitable for selection based on weight reduction of the prototype within the available material. Its Poisson's ratio is 0.3 and possesses hardness number of $95 \mathrm{HR}$ B. Further its maximum strength is $193 \mathrm{GPa}$. So it can be made sure that the material can withstand considerable stress without failure. Thus GI steel is used as the material for main bars, angular links and straight links.

The next selection was for providing power source for climbing and gripping. For climbing and gripping, we chose linear electrical actuators. Electrical linear actuators were chosen because it is noise less, pollution free and easy to supply power as it operates on a $12 \mathrm{~V}$ DC battery. Here, three actuators were used. The specifications of the actuators were primarily based on their stroke length. Two of them having a stroke length of $150 \mathrm{~mm}$ were used for gripping mechanism as it would require only $150 \mathrm{~mm}$ stroke length maximum to hold on to the tree firmly. These actuators are capable of providing a maximum force of $4000 \mathrm{~N}$. The third actuator used as the central body has a maximum stroke length of $400 \mathrm{~mm}$ as it is required to climb maximum safe distance vertically up or down along with the gripper mechanisms. It has the capability of providing a maximum force of $6000 \mathrm{~N}$.

\subsection{Product Parts}

\subsubsection{Main Bar}

It is a rectangular bar of 50x20 mm cross section and having a length of $500 \mathrm{~mm}$. There are two holes of $10 \mathrm{~mm}$ diameter from $150 \mathrm{~mm}$ from the centre to either side of the bar. The two angular links are pivoted on the main bar at these points. Holes are also provided at the centre of the main bar for clamping the linear actuator on to it. The main bar is made of GI steel. Two main bars are used, which are fixed on the top and bottom of the central body. It acts the base for the climbing mechanism. 


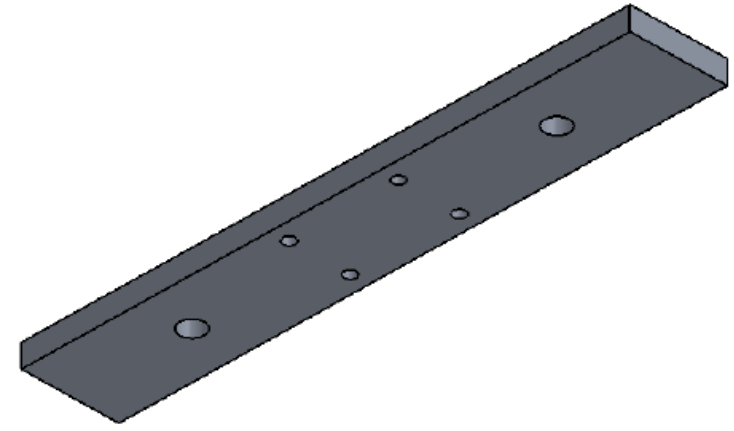

Fig.4.1 Main bar

\subsubsection{Angular Link}

Angular link is one of the important parts of the gripping mechanism. It is an arm like link which is used to hold onto and release from the tree like a human arm. It is also made up of 30x20 rectangular cross sectional GI steel bar. Two angular links are pivoted on each of the two main bars at its centre. At the two ends of the angular links, holes of $10 \mathrm{~mm}$ diameter are provided. One for pivoting gripper and the other for pivoting one end of straight link. There are total of four angular links are in one climber.
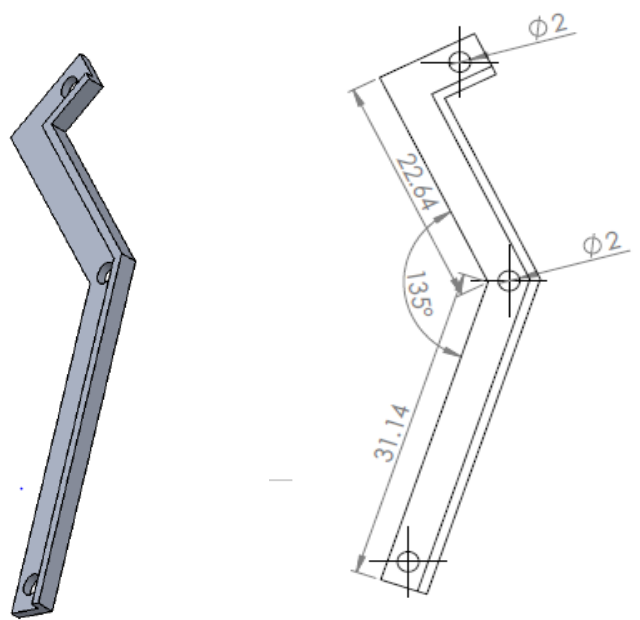

Fig.4.2 Angular Link

\subsubsection{Straight Link}

Straight link is a rectangular cross sectional GI steel bar of $300 \mathrm{~mm}$ length. One end of the straight link is pivoted at one end of the angular link and the other end is pivoted to the linear actuator piston end. There are two straight links in one gripping mechanism. The force applied by the linear actuator is distributed to the angular links through these straight links. There are a total of four straight links; two for each gripping mechanism.

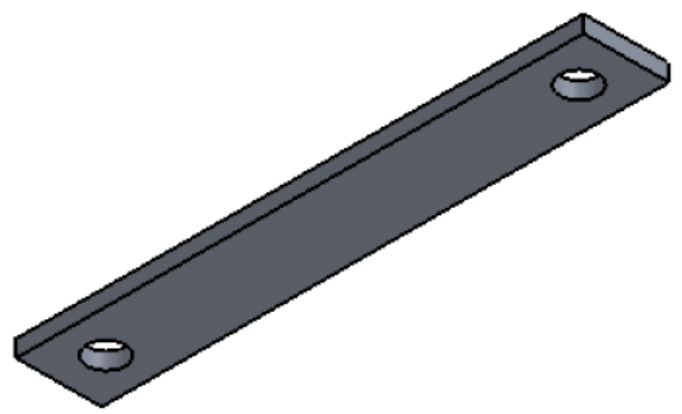

Fig.4.3 Straight link

\subsubsection{Bush}

It is an arc like structure made up of metallic rectangular bar. It acts like a palm of a human being for gripping on the tree surface as the angular links contract together. The bush is pivoted at the free end of the angular link. There are two bushes in a gripping mechanism.

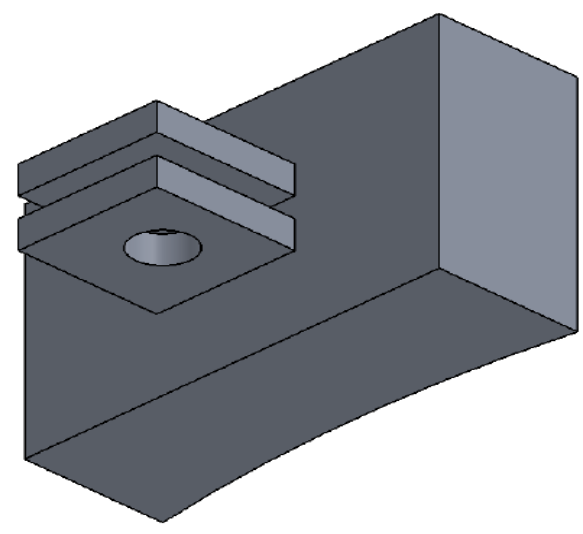

Fig.4.4 Bush

\subsubsection{Central Linear Actuator Cylinder}

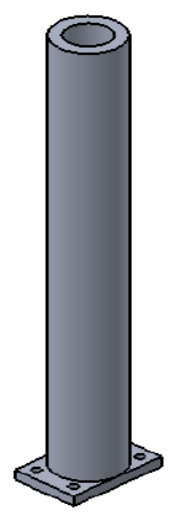

Fig.4.5 Central linear actuator cylinder

It is the cylinder of electrical linear actuator in which the piston of actuator moves up and down. The closed end of the cylinder is fixed on the bottom gripping mechanism at the centre of the main bar through bolting. 


\subsubsection{Central Linear Actuator Piston}

It is the piston of linear actuator of the central body. The free end of the piston is fixed on the upper gripping mechanism at the centre of the main bar.

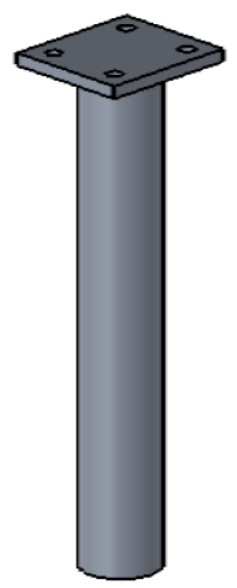

Fig.4.6 Central linear actuator piston

\subsubsection{Gripper Linear Actuator Cylinder}

It is the Cylinder of the linear actuator used in gripper mechanism for the movement of links. The actuator is firmly fixed at the centre of the main bars by means of clamping and bolting.

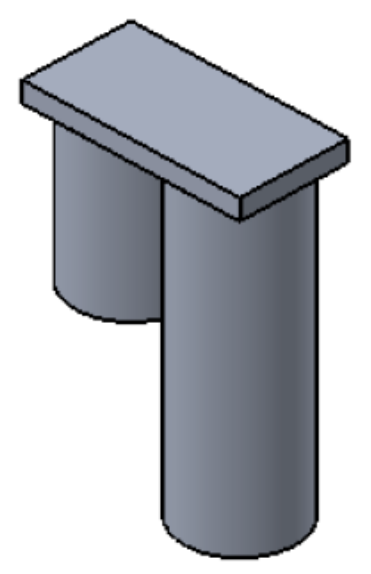

Fig.4.7 Gripper linear actuator cylinder

\subsubsection{Gripper Linear Actuator Piston}

It is the piston of the linear actuator used in gripping mechanism. One end of each straight links in the gripping mechanism is pivoted at the free end of this piston.

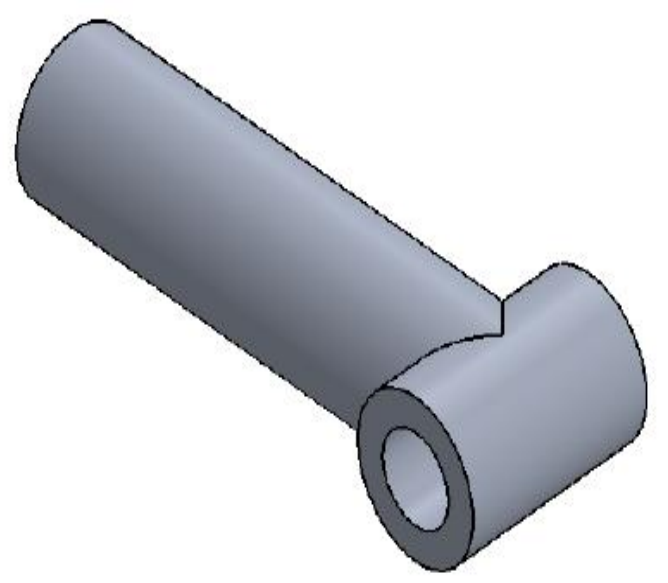

Fig.4.8 Gripper linear actuator piston

\subsubsection{Final Assembly}

The final assembly of the semi automated coconut tree climber is obtained by assembling each part of the product as per the design. The assembly mainly consist of three parts. They are two gripping mechanisms and one central body. The gripping mechanism consists of two angular links, two arms, two straight links and a linear actuator as shown in the figure. One of the two gripping mechanisms is fixed on the top of central linear actuator piston and other one is fixed at the bottom end of Central linear actuator cylinder.

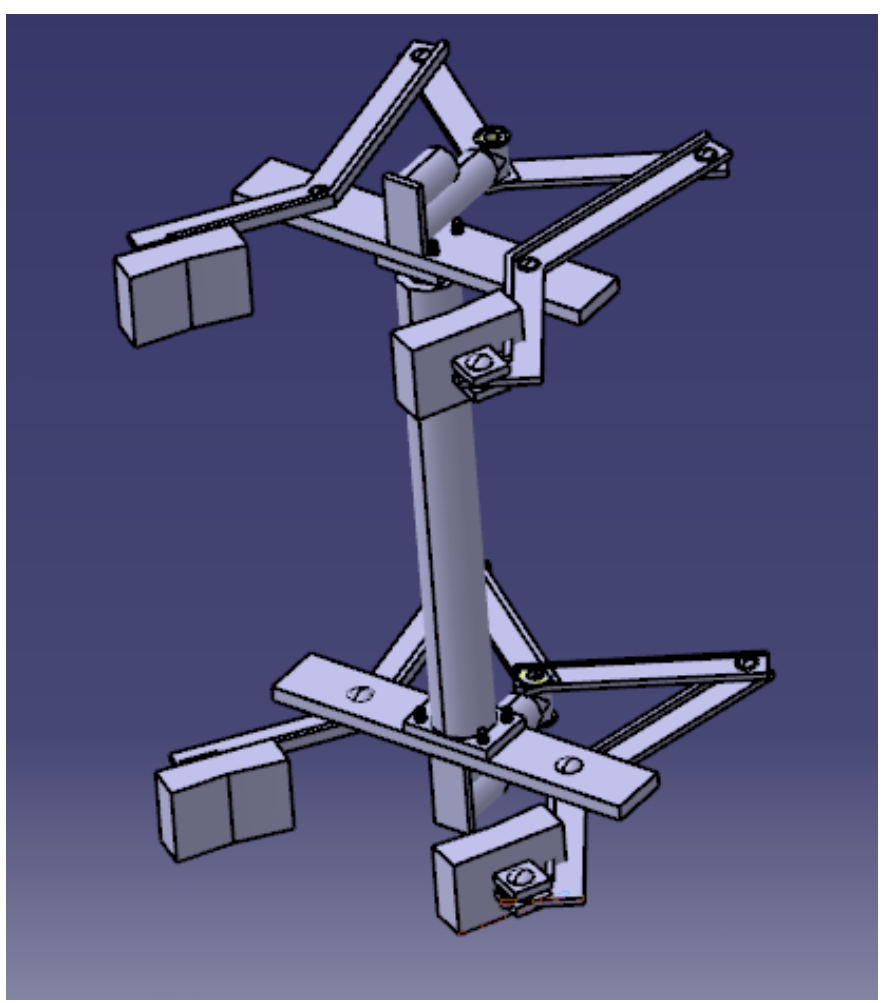

Fig.4.9 Assembly 

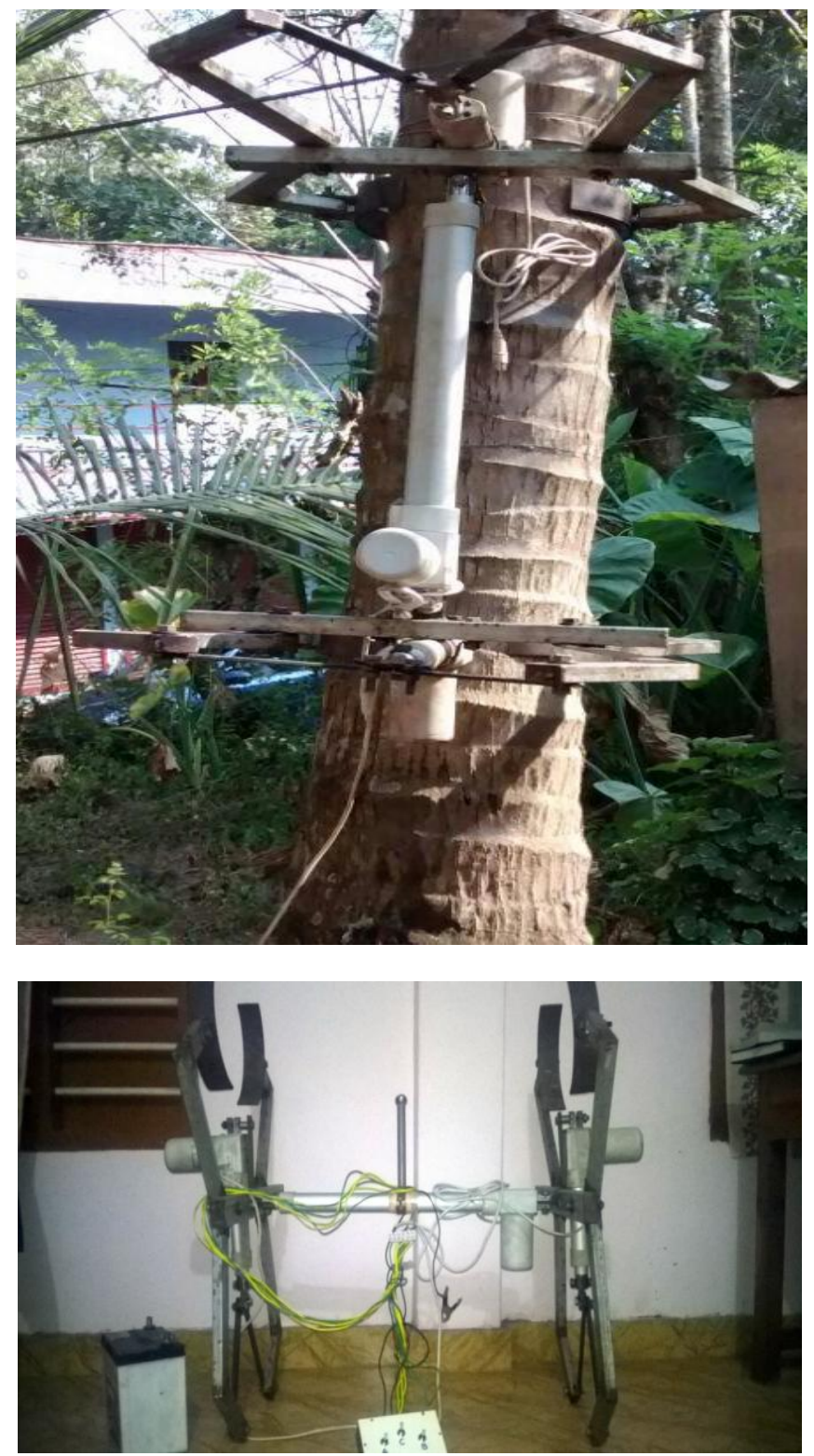

Fig.4.10 Fabricated product

\section{MECHANISM AND WORKING}

Mechanism and working of semi automated coconut tree climber is very simple and easy. There are mainly three parts in this semi automated coconut tree climber. They are two climbing mechanisms and a central body.

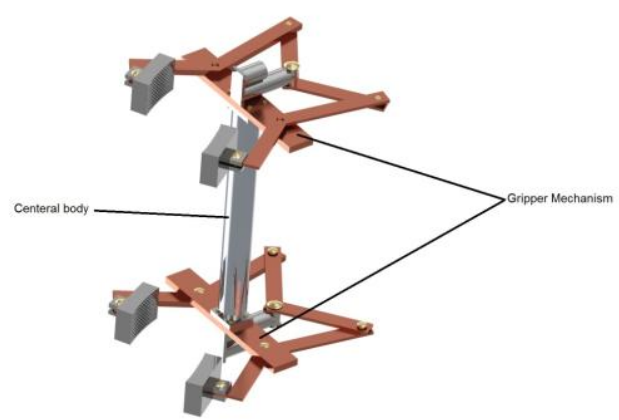

Fig.5.1 Semi automated coconut tree climber
The gripping mechanism is used for gripping and holding on the coconut tree and central body consist of a electrical linear actuator which is used for vertical up and down motion through the tree. Each gripping mechanism is provided on the top and bottom of the central body which is the electrical linear actuator. That is one gripping mechanism is fixed on the top of the piston of linear actuator other one is fixed on the bottom of the cylinder of linear actuator as shown in the figure

\subsection{Main Parts}

\subsubsection{Central Body}

The central body consists of an electrical linear actuator. An electrical linear actuator is a device used for linear inward and outward movement. The actuator consists of a piston, cylinder and a $12 \mathrm{~V}$ DC motor. The $12 \mathrm{~V}$ DC motor is powering a long threaded screw on which the piston moves to and fro. As the motor rotates in one direction, the piston screwed out and on opposite rotation of the motor, the piston moves linearly inward. Thus the outward and inward movement of the piston can be achieved by simply changing the polarity of the motor. For smooth movement of the piston and for reduction of effort, running metallic balls are used between the piston and screw. The linear electrical actuator is designed in such a way that the piston movement can be controlled by electrical signals. The motor gets stopped automatically when the maximum stoke length of the piston is reached. The linear electrical actuator used in the central body is having a stroke length of $400 \mathrm{~mm}$ and a velocity of $15 \mathrm{~mm} / \mathrm{sec}$. It has a maximum capacity of $6000 \mathrm{~N}$.

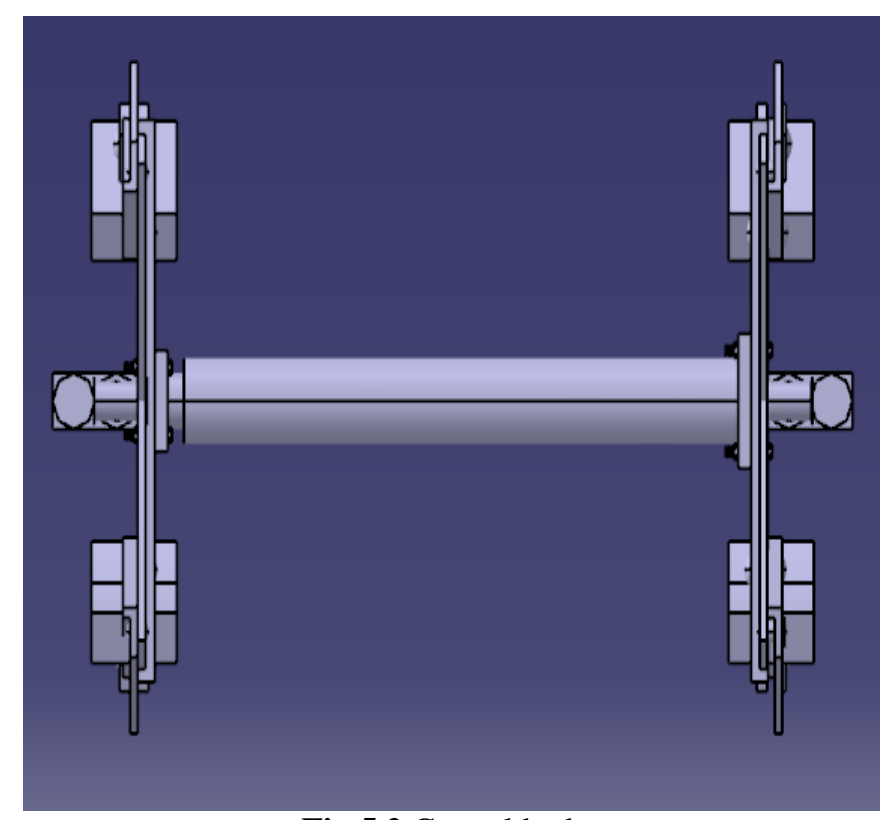

Fig.5.2 Central body 


\subsubsection{Gripping Mechanism}

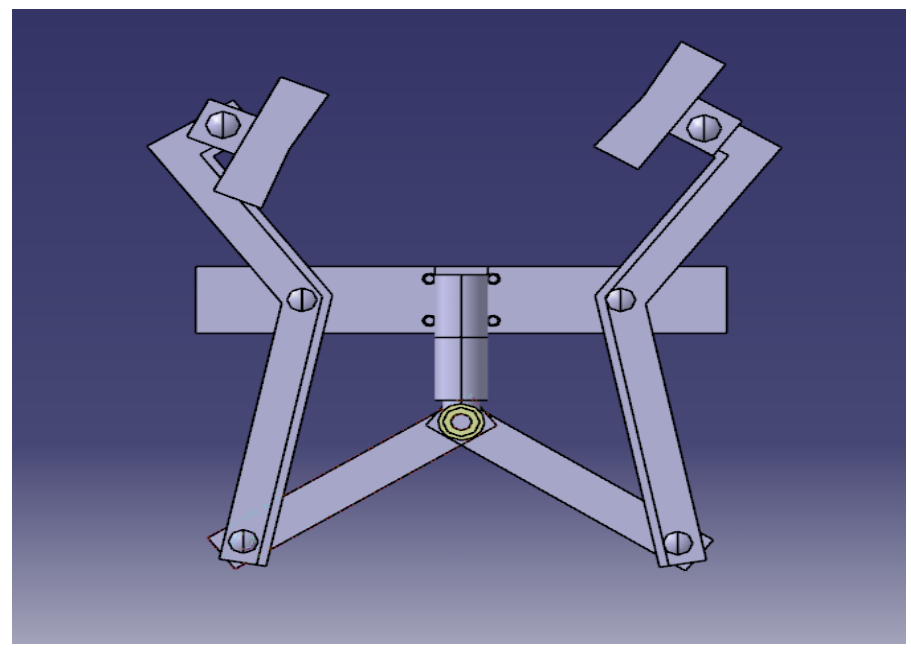

Fig.5.3 Gripping Mechanism

It is the mechanism used for griping and holding on the cylindrical tree surface. The mechanism is a simple link mechanism consisting of four links and a base bar. Rectangular hollow GI steel bar is used for links. There are two angular arm links provided on the base bar, with a $30 \mathrm{~mm}$ distance between them as shown in the figure, to hold on to the tree. These links can rotate about the pivoted points on the base bar. At one end of each angular link arc shaped grippers are provided which comes in contact with the tree surface. Other end of the angular link is connected to a straight rod by pivoted joint. Other end of the straight rod is fixed on the piston end of the linear electrical actuator. The linear actuator used for gripping has a stroke length of $150 \mathrm{~mm}$ and can provide a force of $4000 \mathrm{~N}$. The actuator is fixed firmly at the centre of the base bar by clamping and bolting.

As the piston moves outward, it pushes both angular links through the straight rod at the point of contact of straight link with the angular link. Since the angular link is pivoted on the base rod, it can rotate about it, resulting in contraction of two arms. Thus the mechanism gets gripped on the tree surface. Similarly, as the piston moves inwards, the arms expand and the gripping is loosened.

\subsubsection{Control Unit}

The workings of the linear actuators are controlled using a control unit. It consists of three centre-off-switches. Switches A and B are used for the expansion and contraction of the grippers at the top and bottom respectively. Switch $\mathrm{C}$ is used for the vertical up and down motion of the body.

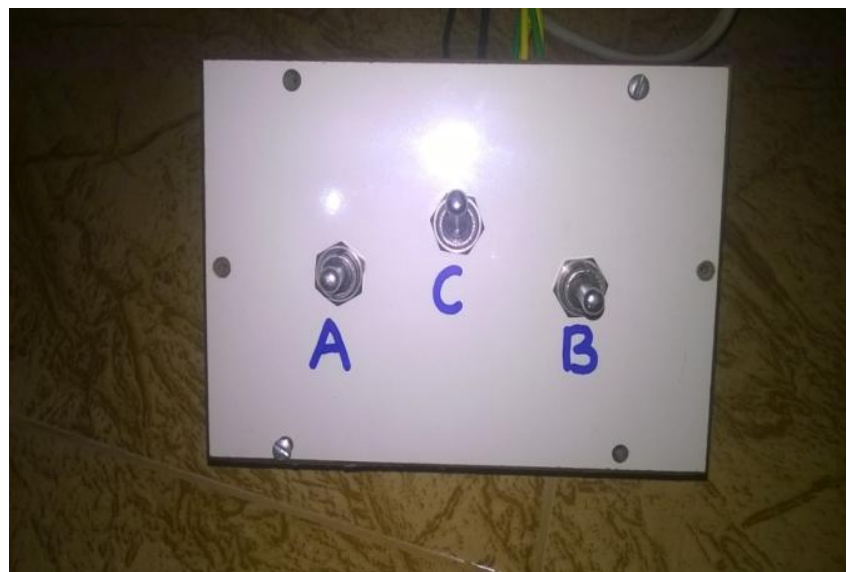

Fig.5.4 Control unit

\subsubsection{Overhanging Arrester}

There is a chance of overhanging of the climber towards the tree due to its self weight while climbing. It becomes difficult to climb on the tree. In order to provide a uniform distance between climber and tree overhanging arrester is used. It is a metallic rod with a roller at its end fixed at the centre of central body. And it is projected towards the tree.

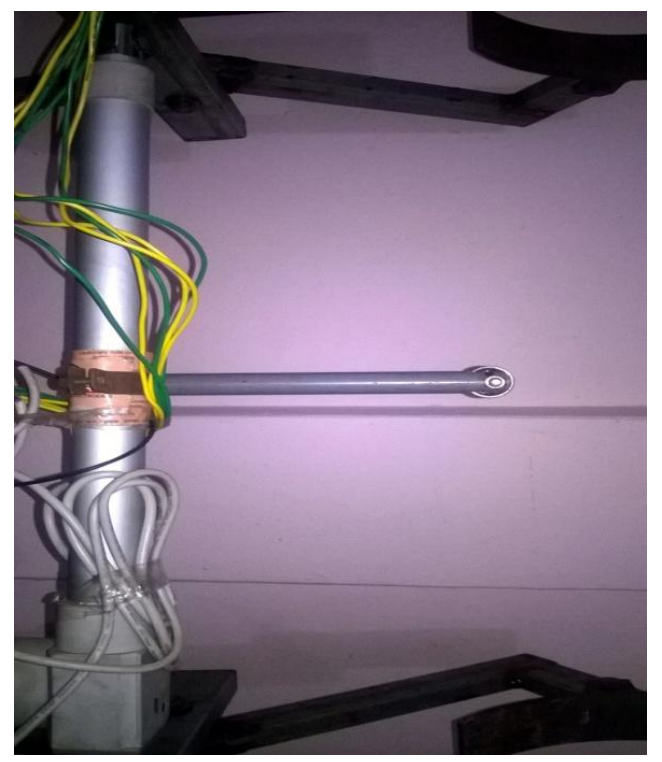

Fig.5.5 Overhanging Arrester

\subsection{Working of Climber}

The climbing mechanism of the semi automated coconut tree climber is very much similar to a man climbing up and down a tree. There are five sequential actions for climbing the tree. They are tightening the lower grip, raising the central body along with the upper gripper, tightening the upper gripper, releasing the lower gripper and finally raising the central body along with the lower gripper.

At first, the lower gripper is fixed on to the tree by operating the switch $\mathrm{A}$ on the control unit. Once the lower gripper is fixed, then the switch $\mathrm{C}$ is operated. By operating switch $\mathrm{C}$, the piston of the central body moves upward to its maximum 
stroke length of $40 \mathrm{~mm}$. Once it reaches its maximum stroke length then switch B is operated to fix the top gripper on the tree. After the top gripper is fixed, the lower gripper is loosened by operating switch A. Finally, switch $\mathrm{C}$ is operated to carry the lower gripper upwards by the backward motion of the central actuator. This cycle of operation is continued till it reaches the top. For climbing downward, first switch $\mathrm{A}$ is operated for losing the lower gripper followed by switch $\mathrm{C}$ for downward motion of the central body. Then again switch $\mathrm{A}$ is operated to hold on to the tree. Next switch B is operated to loose the upper gripping followed by switch $\mathrm{C}$ to carry the upper gripper downward. This cycle of operations are then carried out to climb down.

\section{RESULTS \& DISCUSSION}

\subsection{Static Load Analysis}

The static load analysis were carried out by applying the following conditions.

1. The contact surface of the bush is fixed.

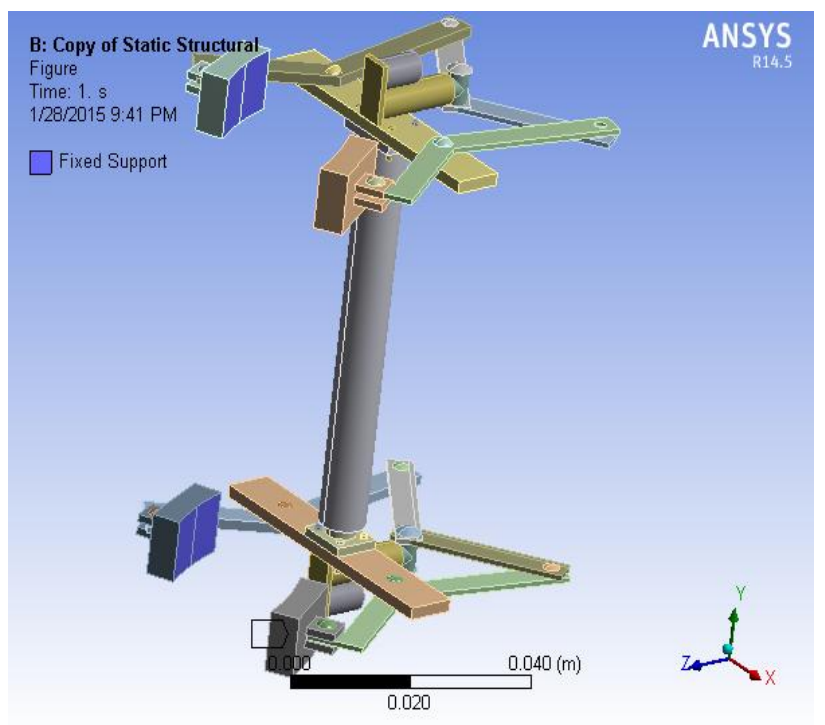

Fig.5.1 Fixed support at the bush

2. Static force applied to the plunger is $20 \mathrm{~N}$.

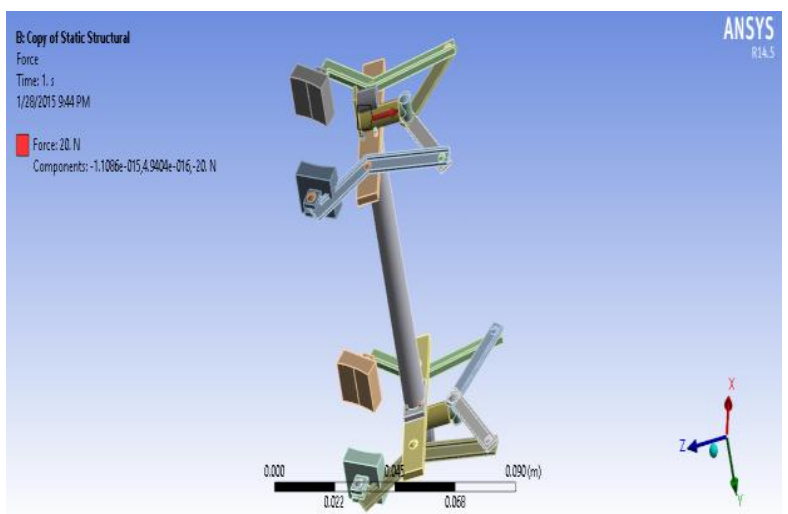

Fig.6.2 Force applied to the gripper linear actuator piston
3. Self weight is acting by gravity.

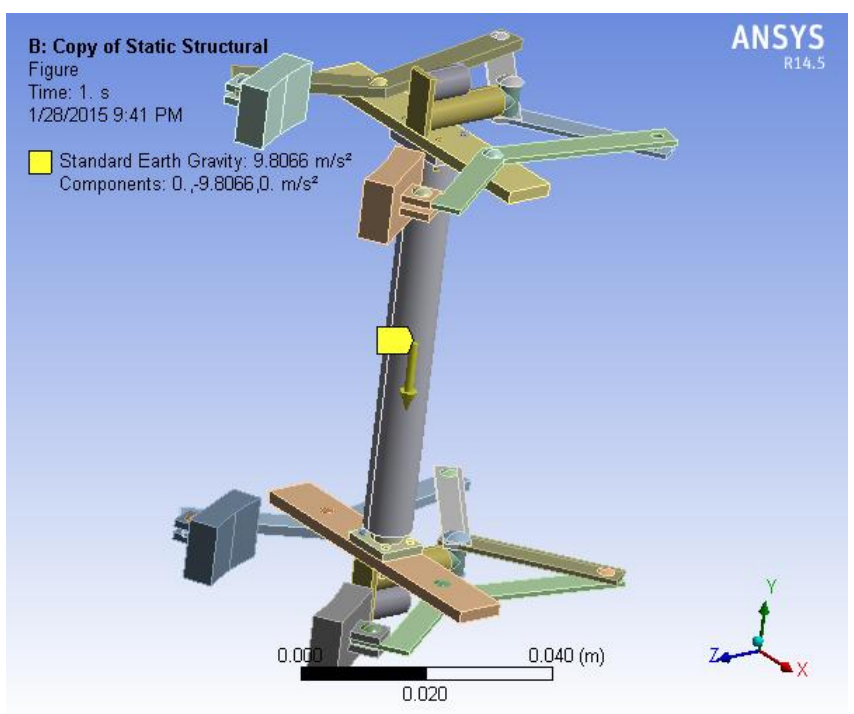

Fig.6.3 Self weight acting on the mechanism

\subsection{Solution}

\subsubsection{Total Deformation}

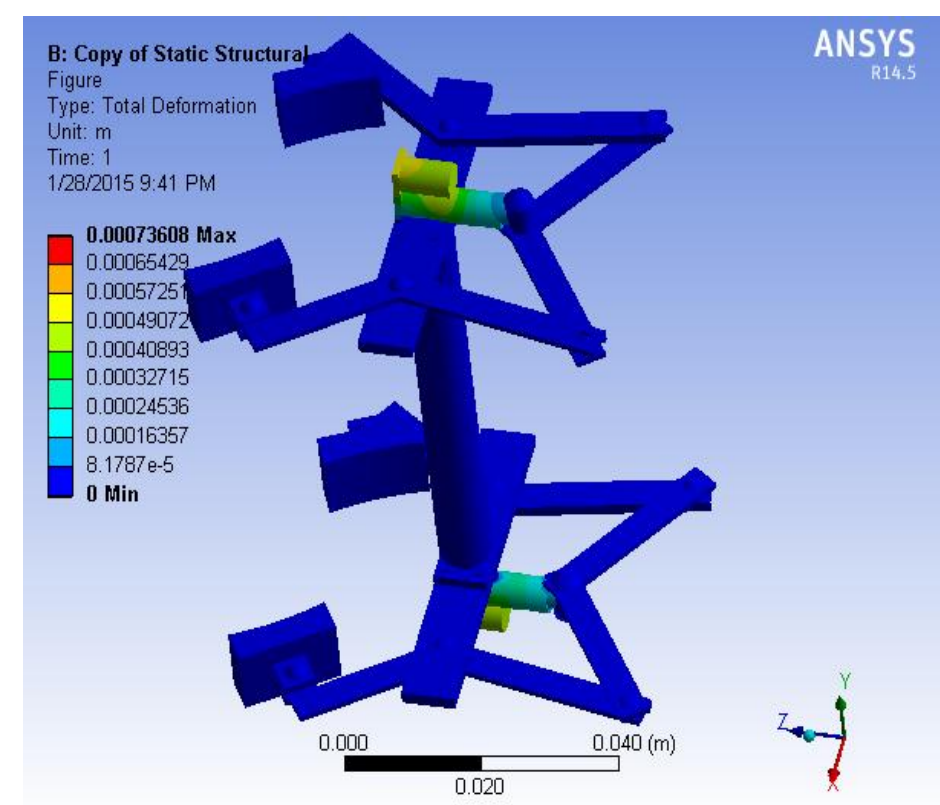

Fig.6.4 Total deformation of the mechanism

Figure shows the total deformation of the structure when a piston force of $20 \mathrm{~N}$ were applied. The maximum value of deformation was $0.736 \mathrm{~mm}$ and it occurs at the piston. The minimum deformation occurs at the bush and its value was found to be zero. Since the deformation value was very low, it was neglected. So the structure was found out to be safe after applying the force. 


\subsubsection{Stress Distribution}

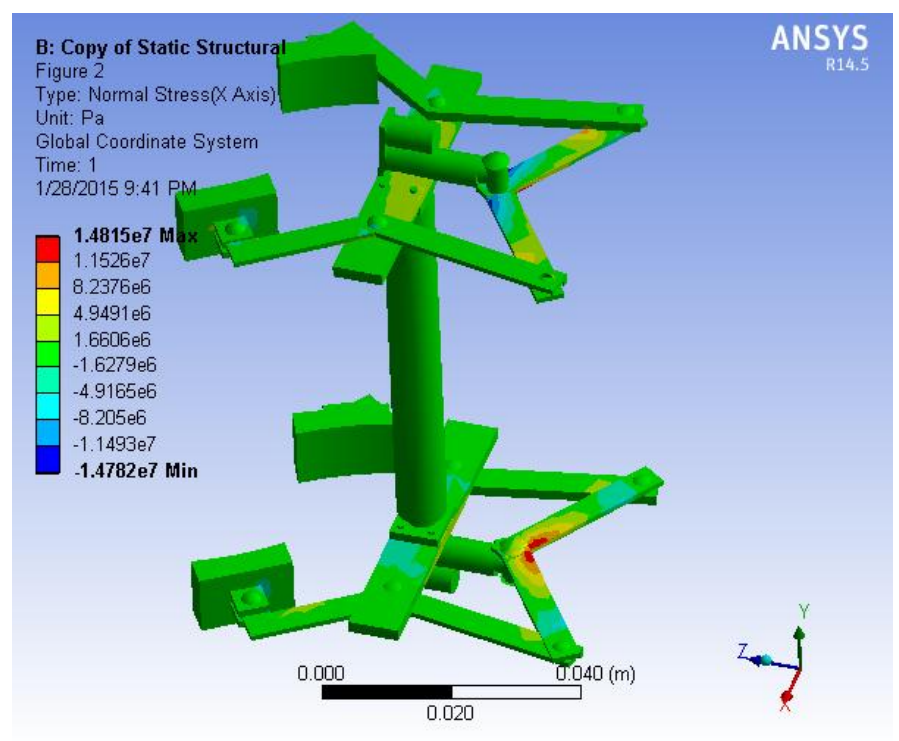

Fig.6.5 Stress distribution on the mechanism

Figure shows the stress distribution on the structure as a result of the force applied. The maximum value of normal stress was $14.8 \mathrm{MPa}$ and it occurs at the region where the straight links are attached to the piston end. The maximum stress was observed at that region were it comes in direct contact with the applied force by the piston. The minimum normal stress occurs at the angular links and its value was found out to be $-14.78 \mathrm{MPa}$. The maximum value were found out to be very much lower than the permissible limit of $193 \mathrm{GPa}$, hence the design was found to be safe under the given conditions and load.

\section{CONCLUSION \& FUTURE SCOPE}

The design of the prototype was done using Solid Works 14 and the static load analysis by ANSYS 14.5. Using trial and error method and static load analysis, suitable material was chosen and fabrication of the prototype was successfully done. From the analysis, the maximum stress was obtained as $1.4815 \times 10^{7} \mathrm{~Pa}$ which is safe and it occurred at the region were the links are attached to the actuator. The prototype was then tested under real life conditions and suitable changes were made to the prototype. The final prototype thus obtained was found to be successful and fully operational.

In the future, the climber can be fully automated. Instead of manual controlling, the whole operation can be programmed into a micro controller. Pressure sensors can be used to determine how much pressure to be applied after the bush comes in contact with the wood. A robotic arm can be used to harvest coconuts. Ph sensors can be used to differentiate between tender coconut and coconut. At present GI steel is used as the material. It can be replaced with aluminium composites or nano fibres which are 10 times stronger and lighter than GI steel.

\section{ACKNOWLEDGEMENTS}

First and foremost, we would like to express our profound gratitude to God Almighty for His immense blessings upon us that led to the successful completion of this project.

We extend our sincere gratitude to Dr. M C Philipose, Principal, Saintgits College of Engineering Pathamuttom, Kottayam, for his support and co-operation throughout this effort.

We are very much thankful to Dr. Sreejith $\mathbf{C} \mathbf{C}$, Head of Mechanical Engineering Department, Saintgits College of Engineering, Pathamuttom, Kottayam for providing us with the guidance and all the facilities for the project.

We express our heartfelt gratitude to our project guide, Mr. Nikhil Ninan, Assistant Professor, Department of Mechanical Engineering for his valuable guidance, support and encouragement during the course of the project and in the preparation of the report. We have greatly benefited from his experience and knowledge.

Help rendered by Mr. Aju Zachariah Mani, Mr. Geo Sebastian and all other staff members of the Department of Mechanical Engineering is thankfully acknowledged.

We also extend our thanks and goodwill to our parents, friends, family members and well wishers for their encouragement and support that helped us to overcome all difficulties.

\section{REFERENCES}

[1] Rajesh Kannan Megalingam, R Venumadhav, Ashis Pavan K, Anandkumar Mahadevan, Tom Charly Kattakayam, and Harikrishna Menon T, "Kinect Based Wireless Robotic Coconut Tree Climber", 3rd International Conference on Advancements in Electronics and Power Engineering ,January 2013.

[2] P. Mohankumar, D. Anantha Krishnan and K. Kathirvel, "Development of ergo refined coconut tree climbing device", African Journal of Agricultural Research, Volume 8, November 2013.

[3] Mani A, Jothilingam A, "Design and Fabrication of Coconut Harvesting Robot: COCOBOT", International Journal of Innovative Research in Science, Engineering and Technology, Volume 3, Special Issue 3, March 2014. 